\title{
Incorporating sustainable development in the design of mineral processing operations - Review and analysis of current approaches
}

\author{
B.C. McLellan ${ }^{\mathrm{a}, *}$, G.D. Corder ${ }^{\mathrm{a}}$, D. Giurco ${ }^{\mathrm{b}}$, S. Green ${ }^{\mathrm{c}}$ \\ ${ }^{a}$ Centre for Social Responsibility in Mining, Sustainable Minerals Institute, University of Queensland, St Lucia, QLD 4072, Australia \\ ${ }^{\mathrm{b}}$ Institute for Sustainable Futures, University of Technology Sydney, Ultimo, NSW 2007, Australia \\ ${ }^{\mathrm{C}}$ Co-operative Research Centre for Sustainable Resource Processing, 26 Dick Perry Ave, Kensington, WA 6151, Australia
}

\section{A R T I C L E I N F O}

\section{Article history:}

Received 4 December 2008

Received in revised form

2 June 2009

Accepted 4 June 2009

Available online 13 June 2009

\section{Keywords:}

Sustainable development

Sustainability

Design

Mineral processing

\begin{abstract}
A B S T R A C T
This paper reviews the tools and methodologies used for incorporating sustainability considerations into the design of mineral processing operations. It was found that while there is a range of tools and methodologies that contribute to Design for Sustainability, there is no consistent, integrated approach to support the mineral industry in incorporating a greater level of sustainability into the design process. This paper identifies the required elements in such an approach and discusses the ways in which its development would progress the industry towards sustainability.
\end{abstract}

(c) 2009 Elsevier Ltd. All rights reserved.

\section{Introduction}

The mineral and metal industry is actively seeking to progress its commitment to sustainability principles by reducing the impacts of its mining and mineral processing operations [1,2]. The biggest opportunity for reducing the impact of operations is in the design phase, rather than in the operation or post-closure phases [3] - hence we will focus in this paper on reviewing the effectiveness of approaches currently available for improving the design (with regard to meeting sustainability objectives) of mineral processing operations. Additionally, we argue that reducing impacts of operations alone is insufficient to progress the industry towards sustainability. Instead, opportunities for impact reduction must be sought along and between production and recycling chains [4]. Furthermore, running more efficient operations does not in itself lead to sustainable development, in particular due to rebound effects relating to the rate and magnitude of metal use associated with consumption and service provision in a sustainable society [5]. To begin addressing the issue, we need to analyze to what degree impacts can be reduced through better design, through efficient operation and through

\footnotetext{
* Corresponding author. Tel.: +61 73346 4048; fax: +61 733464045

E-mail address: b.mclellan@uq.edu.au (B.C. McLellan).
}

supply chain synergies. These are all essential inputs to framing a response to the more fundamental question of how the mineral industry structures its operations and business models to support truly sustainable development.

Following an examination of the sustainability agenda within the industry to emphasise the motivation for this research, the remainder of the paper will review current tools and approaches for integrating sustainability principles into mineral processing design. The conclusions from the paper outline research gaps meriting further attention and are developed with respect to how adequate the current tools and approaches are for progressing stated sustainability aspirations of industry and, importantly, the role that improved design will play compared with broader approaches that aim to reposition the industry as an integral part of a sustainable society.

\subsection{Minerals and sustainability}

This section focuses on sustainability definitions relevant to mineral and metal processing and identifies key tensions and prevailing themes. The purpose of this discussion is to show that the sustainability need as defined by industry, is directly related to the tools which have been developed to date. Following a review of currently available tools (Section 2), we argue that new tools need to be developed (Section 3) and the reason that they do not currently exist is due in part to inadequate problem definition. 
Definitions can be grouped into two broad themes covering:

- resource use and management and

- minimising impacts associated with resource use.

A focus on resource use and management features in broad sustainability frameworks such as the Natural Step [6] which sets principles for the rate of resource use which can be sustained over time, and broadly minimises the resource throughput for "meeting human needs". Here, minerals and metals are considered alongside other resources as inputs to the economy. Consideration of resource use and management within mineral-specific frameworks are discussed further in Section 2.2.1. Dematerialisation [7] literature also has a focus on reducing the total resource throughput for delivering services required in our society, although the nature of the services receives varying degrees of attention. A key tension for resource use and management is whether metals are viewed as part of either a "fixed stock" or "opportunity cost" paradigm [8]. Scientists and ecologists generally approach resource management from the perspective of a "fixed stock" of non-substitutable resource which ought to be better managed, for example by applying industrial ecology principles and 'closing the loop' to focus on recycling. On the other hand, mineral economists have tended to embrace the "opportunity cost" paradigm where resource depletion - for any class of metals - will lead to scarcity, higher prices and the development of new technology to exploit lower grade ores or the substitution of metals with other materials to provide required services. There are two shortcomings of the opportunity cost paradigm, first, a reliance on new technology to access lower grade ores ${ }^{1}$ and second, many metals have unique properties and may not be readily substituted.

Several researchers have focussed on when we might 'run out' of metals in the ground [10], and whilst recent research shows the phenomenon of peak metals [11], Stewart and Weidema [12] argue that metals are unlike other resources in that their atomic structure means they are inherently recyclable, given sufficient energy input. Certainly the impacts associated with re-concentrating dissipated uses of metals are considerable, uneconomic and come with high impacts given current energy technology, in a sense defining 'practical' resource exhaustion, but from a theoretical perspective metals are very different to other resources such as coal or oil. Beyond land-based ores, there are also ocean resources, and in-use and discarded stocks of metals in cities which all represent future sources. This distinction underpins the way in which we consider sustainability for metals, not primarily in terms of resource depletion (as might be pertinent for oil), but rather in terms of the magnitude and location of impacts associated with cycling metals through the economy.

The second theme of sustainability definitions relates to reducing impacts associated with metal-producing activities of mining and minerals processing. These efforts have been driven by the Global Reporting Initiative, regional constraints (e.g. water scarcity in Australia) emission trading systems (accounting for carbon intensity), typically focussed at the plant scale. The triple bottom line $(\mathrm{TBL})^{2}$ approach features heavily. There is usually an emphasis on reducing the environmental impact, per tonne of product [13], with

\footnotetext{
1 The mineral industry can be risk averse to the uptake of new technology due to the high capital cost of equipment and also due to iconic examples of underperformance of new technologies, e.g. nickel laterite processing using high pressure acid leach technology [9].

2 The triple bottom line refers to balancing economic prosperity, environmental quality and social justice in assessing the performance of projects and companies. Promoted by Elkington (1998) to demonstrate that sustainability goes beyond trying to reconcile only the financial and environmental bottom lines.
}

little attention directed to the total amount of emissions or the context in which those emissions occur [14,15]. For example, an operation can conceivably reduce its $\mathrm{CO}_{2}$ emissions per tonne of product, but if the number of tonnes of product increases sufficiently the operation's total $\mathrm{CO}_{2}$ emissions will increase, thus making a larger contribution to global warming. Furthermore, little consideration is given to the current and future roles of metals in providing services in the economy. There is some consideration across life cycle phases (Fig. 1), particularly with respect to remediation of plant sites, but little along supply chains [16]. Looking into the future, the mineral industry may need to further position itself to adapt to stewardship of minerals beyond their initial societal use, with recycling and reuse as key elements of a sustainable "closed-loop" society.

Some of the complexity of life cycles for mineral products is shown in Fig. 1. Given that the pre-operational phases of planning and design are where the greatest potential improvement in the operation's lifetime sustainability impacts can be made, this paper covers a review of tools predominately utilised in these early phases of the project cycle, especially across the design phase. However, despite this potential for improvement, sustainable design of mineral industry projects has not been widespread or thoroughly examined. A body of literature exists on each of the production (extraction, processing, use and waste management/recycling) and closure (decommissioning, remediation and restoration) (e.g. ICMM [17]) phases, but this has not been examined here.

The approach taken to sustainability or sustainable development (SD) here is to assume that mining and mineral processing operations will continue to be necessary and that improvement in operational methodologies - through all life stages of the operation and product - are also a necessary component of ensuring long term viability under environmental, social, governmental and economic constraints. Tools and methodologies are the focus of this review, and are examined based on their capacity to assist in the design and analysis of operations to assist with achieving sustainable development.

The review of approaches within this paper is important input to the first stages of a proposed two-stage path toward increased sustainability. Informed by the gaps identified in this review, the first stage would engage with industry, government and the community in developing structured approaches to reduce triple bottom line impacts in the design of new processes, with greater emphasis along production cycles and phases. Whilst limited in the extent to which it alone will bring about sustainable development, it is an essential process for

- realising tangible reductions in triple bottom line impacts

- understanding the potential of design for sustainability in new minerals processes

- highlighting the remaining challenges with

o existing minerals processing and economic infrastructure and

o the ultimate drivers of production and consumption cycles in the wider economy.

The second stage would then be to re-imagine a sustainable economy and the role the mineral industry will play in supporting this, including new business models based on the provision of services for a sustainable economy.

\section{Design for Sustainability}

Design for Sustainability (DfS) is a term that has been used little in the process and mineral industries, but more frequently in the construction and manufacturing industries to indicate product 


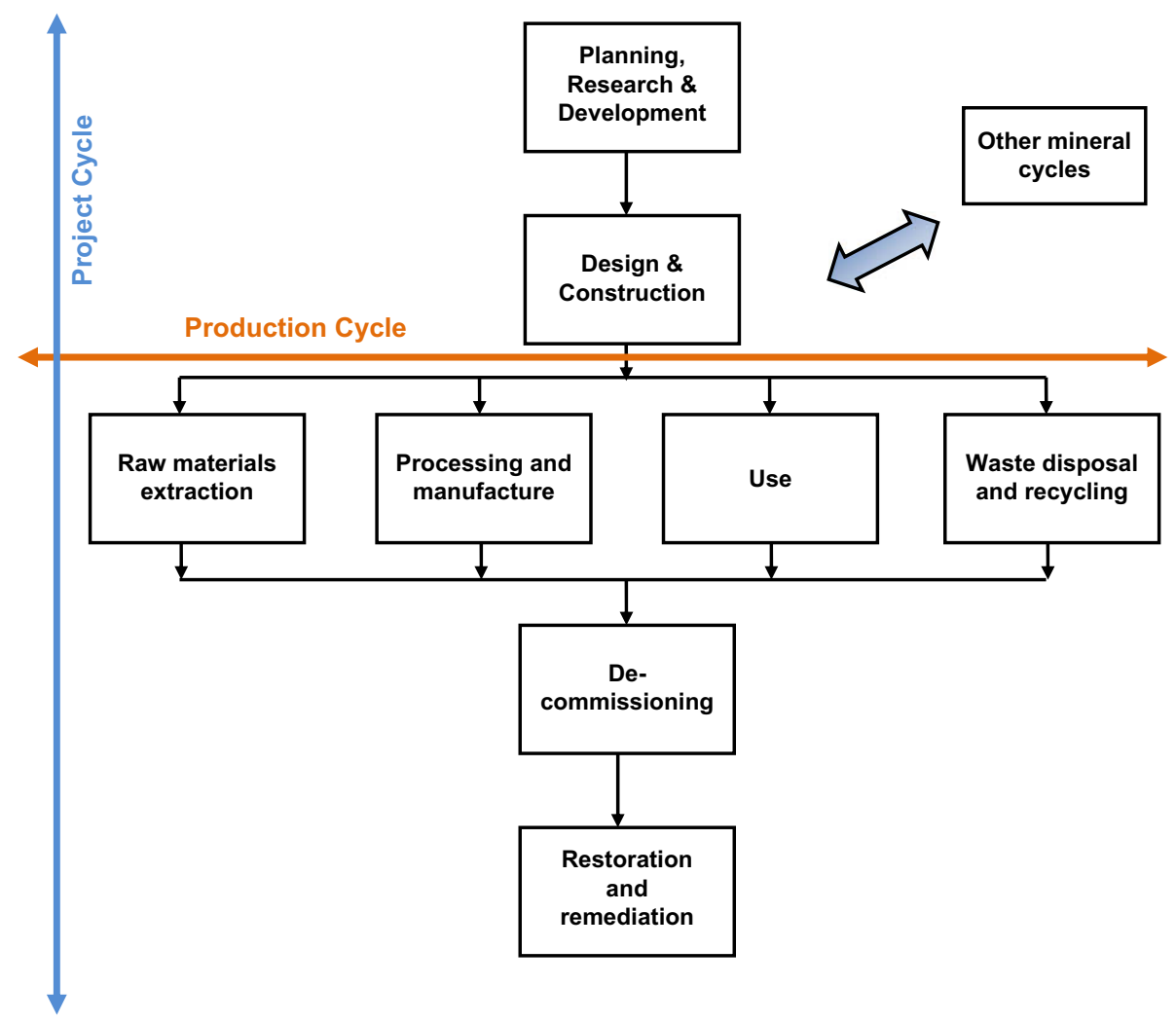

Fig. 1. Project and production cycles of mineral products after Allen et al. [96].

design for sustainability $[18,19]$. Because of its newness to the process industry, we wish to stress here that DfS goes beyond Design for Environment (DfE) to reflect the triple bottom line criteria (which incorporates social, environmental as well as economic criteria - refer to footnote 2 ) into process design. It could be defined as: design that takes into account social, economic and environmental impacts and constraints and aims to produce the most benefit for society, whilst minimising negative impacts and not violating any of the critical thresholds or the carrying capacity of the society and environment, across the life cycle of the project and the product. This review examines the key tools to support a DfS approach as they currently stand, and the place they hold within the project development cycle.

DfS is an important opportunity for improving SD outcomes over the life of the operation. In practice, activities which could fall under the DfS definition have been viewed as a secondary element of operations design, with the main focus being typically on how to design an operation that will effectively extract the target minerals at the lowest possible capital cost and lowest risk. Sustainability issues within the minerals industry have historically been viewed from a "compliance" perspective, with very little importance placed on their integration into design $[20,21]$. Furthermore, it is apparent that little experience and systematic implementation of a completed DfS methodology has been undertaken [21].

Whilst some interest has been drawn to the environmental aspects of DfS, less consideration is given to the social impacts of engineering design [22]. The main allowance for the social factors is indirectly through interest in health and safety and the reduction in emissions of toxic waste products. This reflects the perceived difficulty in quantifying social indicators, and the question of whether appropriate connections can be drawn between operation designs and social impacts. Furthermore, most of the existing sustainable design work is in the general process engineering field, rather than the minerals industry specifically.
Examining the available tools contributing to sustainability assessment and DfS, it is apparent that they can readily be grouped in terms of the project phase of application and the elements of sustainability addressed. It is also apparent that, in terms of the elements of sustainability, the majority of tools address environmental issues only. Fig. 2 shows the examined tools overlayed onto the production and project phases of a minerals industry project. The phases of key interest in this review are the planning phase (taking in the baselining of the host environment and community of the project) and the design phase (broken down here into design, costing and decision-making elements, although these may often be interlinked). Table 1 gives descriptions and key references for the tools shown. Some tools cross-over between phases, as indicated by gradated colouring in Fig. 2, however, they are described in the phase in which they appear most commonly.

\subsection{Criteria for assessing the efficacy of SD design tools}

Having examined the literature and collated the available sustainability tools, it was recognised that in order to determine where gaps and synergies exist it was important to describe the key characteristics necessary for tools at each phase. No equivalent set of criteria was found to have been completed for the task of process industry design, with the nearest equivalent being the "Bellagio Principles" for assessment of progress towards SD [23]. Hence, the following set of criteria are proposed by the authors, based on an understanding of key elements of sustainability (Table 2). The currently available sustainability tools are then assessed against these criteria in subsequent sections.

\subsection{Project planning phase}

The project planning or prefeasibility phase of an operation's life cycle provides the initial opportunity to implement sustainability 


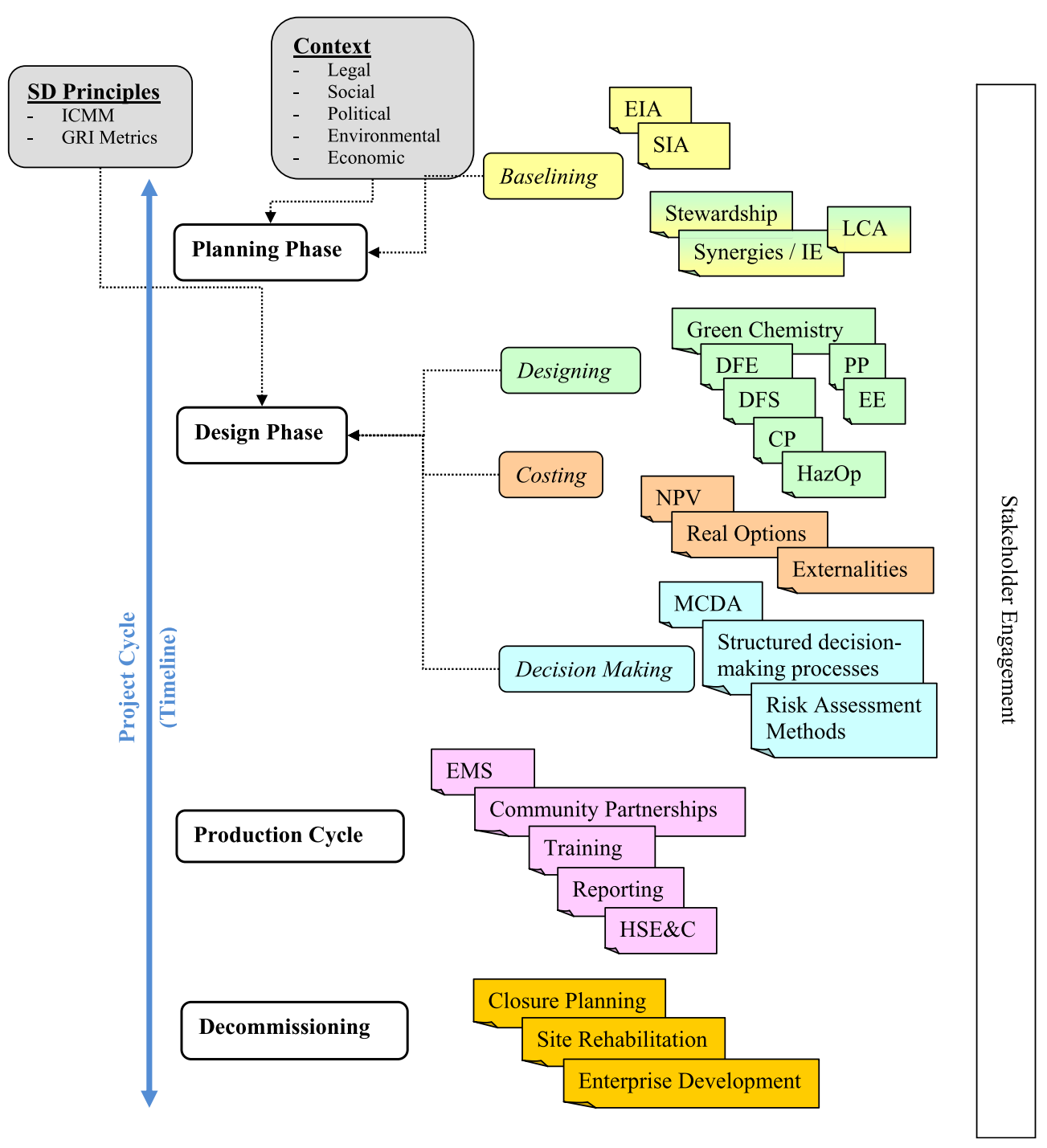

Fig. 2. SD tools and their place in the life cycle of an operation.

principles. Many of the tools utilised at this stage are focused on determining the baseline for the local environment and community, and identifying issues of concern or potential impact, which can be mitigated.

\subsubsection{Sustainability frameworks}

A number of major, global and national initiatives have developed frameworks and criteria for measuring sustainability across the mineral industry. These frameworks could form the basis for sustainability integration into design and operation of a mineral processing project, and hence are essential planning phase elements of a sustainable design methodology. SD principles and frameworks can assist in guiding or prompting designers or planners in directing their efforts towards incorporating SD in the operation.

On examination of the literature, there are three general frameworks that stand out. These are as follows.

- Mining, Minerals and Sustainable Development (MMSD) project [2] (and its "Seven Questions to Sustainability" framework [24] in terms of the practical application - although these do not directly align).

o The MMSD has a strong focus on governance and companycommunity interaction in decision making, but does not address environmental or social issues in much detail. The
7Q's approach has a much more complete framework in place - extending from principles through to actual indicators, however, the qualitative nature of some aspects may make comparisons difficult.

- International Council on Mining and Metals (ICMM) sustainability principles [25], in conjunction with the "Enduring Value" implementation guidance [26], and the Global Reporting Initiative (GRI) metric system [27,28] as a possible application-end framework as mentioned in "Enduring Value" [26].

o The ICMM framework is focussed on implementation, and is thus useful in regard to practical projects, although it may be overly inclusive in its classification of sustainable development in some cases, whilst neglecting other important issues such as land usage and by-product impacts.

- Battelle's sustainable business decision framework [29]

o Battelle's SBDF is not as specific in the categories of sustainability impact as the previous two frameworks. It has a very strong stakeholder identification aspect, which could potentially assist to maintain the focus of the design or assessment on the specific impacts of the operation.

A large number of fundamental principles of sustainability for the mining sector have also been developed by the UNEP [30] and others [23,31-33]. These principles are useful as a guide to 
Table 1

Descriptions of sustainability tools across the project and production cycles of an operation.

\begin{tabular}{|c|c|c|c|c|}
\hline & & Tool & Approach and description & Examples \\
\hline \multirow[t]{8}{*}{$\begin{array}{c}\text { Planning } \\
\text { phase }\end{array}$} & \multirow[t]{3}{*}{ SD principles } & MMSD & $\begin{array}{l}\text { Mining, Minerals and Sustainable Development - principles for SD in the minerals industry, } \\
\text { with the "Seven Questions" assessment framework }\end{array}$ & [2] \\
\hline & & ICMM & International Council on Mining and Metals - framework of SD principles for mining companies & {$[25,26,56]$} \\
\hline & & SBDF & $\begin{array}{l}\text { Sustainable Business Decision Framework - approach using matrices of stakeholders to identify impacts } \\
\text { of a business or project }\end{array}$ & [29] \\
\hline & \multirow[t]{5}{*}{ Baselining } & EIA & $\begin{array}{l}\text { Environmental Impact Assessment - assessment of potential impacts of operation } \\
\text { on surrounding environment; can included opportunities for mitigation and alternative sites; } \\
\text { legally required in Australia. }\end{array}$ & {$[34,35]$} \\
\hline & & SIA & $\begin{array}{l}\text { Social Impact Assessment - assessment of the potential or actual impacts of an operation } \\
\text { on the local community }\end{array}$ & {$[36-38]$} \\
\hline & & Stewardship & $\begin{array}{l}\text { Ensuring that materials are produced safely and used efficiently across the many phases } \\
\text { of their production and use. }\end{array}$ & {$[55,97]$} \\
\hline & & LCA & $\begin{array}{l}\text { Life Cycle Assessment - inventory and analysis of the inputs and outputs of each phase of the life } \\
\text { of a product or process. }\end{array}$ & {$[50-54,60]$} \\
\hline & & IE & $\begin{array}{l}\text { Industrial Ecology - using synergies between inputs and output waste streams of industrial } \\
\text { plants to reduce their combined impact. }\end{array}$ & {$[39,40]$} \\
\hline \multirow[t]{13}{*}{$\begin{array}{l}\text { Design } \\
\text { phase }\end{array}$} & \multirow[t]{7}{*}{ Designing } & Green Chemistry & $\begin{array}{l}\text { Finding routes for production of chemical products that utilise less hazardous materials } \\
\text { and overall less resources. }\end{array}$ & {$[47,98]$} \\
\hline & & DfE & $\begin{array}{l}\text { Design for Environment - methodologies for incorporating environmental considerations } \\
\text { in industrial design to reduce impacts. }\end{array}$ & {$[20,21,41-47,49]$} \\
\hline & & $\mathrm{CP}$ & Cleaner Production - aims at reducing the energy and materials impacts of processes. & {$[72,73]$} \\
\hline & & EE & Eco-efficiency - the energy and materials impacts of a process. & {$[72-75]$} \\
\hline & & DfS & & - \\
\hline & & PP & Pollution Prevention - steps to reduce the pollution produced by the operation. & [61-65] \\
\hline & & HAZOP & Hazards and Operability studies - a methodical process for eliminating safety hazards from operations. & {$[99,100]$} \\
\hline & \multirow[t]{3}{*}{ Costing } & NPV & Net Present Value - the standard technique for valuation of operations. & \\
\hline & & Real Options & Can be used to evaluate the opportunity cost of SD innovations or flexibility in project design. & {$[85,87]$} \\
\hline & & Externalities & $\begin{array}{l}\text { Incorporation of environmental and other costs (into the cost of the project) that are not involved } \\
\text { in a typical NPV analysis. }\end{array}$ & {$[77,78,82]$} \\
\hline & \multirow[t]{3}{*}{$\begin{array}{l}\text { Decision } \\
\text { making }\end{array}$} & MCDA & $\begin{array}{l}\text { Multi-Criteria Decision Analysis - used to compare options with multiple performance criteria } \\
\text { (e.g. environmental, economic, social). }\end{array}$ & {$[34,88-92]$} \\
\hline & & $\begin{array}{l}\text { Risk Assessment } \\
\text { Methods }\end{array}$ & Can be utilised to determine the relative risk and potential benefits of different project options. & {$[76,101,102]$} \\
\hline & & $\begin{array}{l}\text { Structured decision } \\
\text { making }\end{array}$ & Decision-support frameworks can be used to manage the decision process in a transparent manner. & [93-95] \\
\hline
\end{tabular}

framework development, but they tend to be less rigorously evaluated than the 3 frameworks reviewed here. Yet there is no obvious reason why these principles could not be incorporated into the above-mentioned frameworks.

Sustainability indicators and metrics have been developed for various levels of assessment between the individual operation and the corporate level. However, the consistency and interaction between the frameworks employed at each level does not seem to have been addressed in the majority of cases. It would be ideal for an SD framework to be smoothly connected from the corporate to the operational level, with two-way information flows and goalsetting, however, this has not been observed in the current literature. As a result, there appears to be an opportunity to develop such a methodology that would incorporate sustainability principles into the design and operation of mineral processing plants.

\subsubsection{Baselining}

The baselining aspect of the planning phase is aimed at understanding context and creating a reference point for the development of the project, and mitigation of potential impacts. Typically the studies are once-off, and require a high level of research intensity, data collection and analysis, and stakeholder involvement. In creating more sustainable operations, the baseline and the local environmental limitations are highly important for measures of performance.

Environmental Impact Assessment (EIA), or the like, which is widely applied in the mineral industry $[34,35]$, is specific to the particular operation, and is often used to provide context to the potential operational impacts, as well as comparison of alternatives in environmental terms. In the mineral industry, especially the mining element of the mineral life cycle, location-specificity is of particular importance in creating tailored, sustainable designs for operations. Unfortunately, EIAs are, in general, currently undertaken too late in the design process, and may result only in "end-ofpipe" changes in design to meet regulatory requirements.

Social Impact Assessment (SIA) is commonly recognised as the "weakest" pillar of sustainability assessment due to the lack of easily applicable quantification techniques [36]. It has largely developed as an element or offshoot of EIA [37]. Various authors have developed methodologies which attempt to offer standard, general assessments and bring rigour to SIA, whilst some authors argue that no single methodology is adequate [37].

Joyce and MacFarlane [38] indicate that some success has been seen in the application of SIAs in mining projects. They also observe that the direction of SIA is moving towards a combination of a technocratic (expert-driven) process of assessment, and a community-consultation methodology, which hopefully allows a merging of the quantitative and qualitative, objective and subjective aspects of SIA.

Industrial ecology (IE) is another approach that can supplement a baselining study, or contribute to design of a project, although it is not frequently applied. It involves the linking of industries in the same geographical locality to take advantage of the possibility of waste material and energy exchanges, and shared infrastructure 
Table 2

Criteria for assessing the efficacy of SD design tools.

\begin{tabular}{|c|c|c|}
\hline Phase & Key requirements & Additional considerations \\
\hline Project planning & $\begin{array}{l}\text { 1. Understanding of sustainability concepts. } \\
\text { 2. Understanding of the baseline context of the project - key stakeholders, } \\
\text { community, local environment, economy and their interactions. } \\
\text { 3. Predicting potential impacts or benefits on the environment, society } \\
\text { and economy at different scales. } \\
\text { 4. Understanding of the limitations of the local environment and community, } \\
\text { and any synergies that might assist the project or be supported by it. } \\
\text { 5. Understanding stewardship issues across product and project } \\
\text { life cycle phases that could require or impose external or indirect impacts. } \\
\text { 6. Long term viability of environment, society and economy } \\
\text { with or without project - risks assessment. }\end{array}$ & $\begin{array}{l}\text { A. Developing a stakeholder engagement plan; } \\
\text { B. Determining metrics for the measurement of SD performance; } \\
\text { C. Necessity of project; } \\
\text { D. Effectively communicate/carry-over learnings to design } \\
\text { and operations phases; }\end{array}$ \\
\hline Design & $\begin{array}{l}\text { 1. Incorporate/integrate planning phase understanding. } \\
\text { 2. Understanding the effect of design choices on direct } \\
\text { and indirect SD impacts of the project: } \\
\text { i. Environmental emissions and resource usage across the product } \\
\text { and project life cycle. } \\
\text { ii. Onsite and offsite effects. } \\
\text { iii. Closure and recycling impacts. } \\
\text { iv. Industrial and social synergies. } \\
\text { v. Waste reduction/by-product reuse. } \\
\text { vi. Construction and operational impacts. } \\
\text { vii. Deviation from baseline impacts and social/environmental limitations. } \\
\text { viii. Human/environmental/economic costs and benefits. } \\
\text { 3. Creation and comparison of alternatives based on SD impacts. } \\
\text { 4. Incorporation of stakeholder input. } \\
\text { 5. Costing methods including non-financial SD impacts. } \\
\text { 6. Optimisation and decision-making based on an inclusive SD approach. }\end{array}$ & $\begin{array}{l}\text { A. Innovation. } \\
\text { B. Best practice technologies. }\end{array}$ \\
\hline Operation & $\begin{array}{l}\text { 1. Development of SD indicators and reporting and ongoing improvement } \\
\text { against these indicators } \\
\text { 2. Stakeholder relationship } \\
\text { 3. Management, training and reporting systems }\end{array}$ & \\
\hline Closure & $\begin{array}{l}\text { 1. Planning for closure } \\
\text { 2. Rehabilitation and social initiatives }\end{array}$ & \\
\hline
\end{tabular}

$[39,40]$. The industrial ecology approach (and the regional synergies subset) reflects the connectedness of any individual operation to its local environment (in this case the industrial environment), which is a key element of sustainability thinking.

These planning phase tools can be utilised to support the design of operations that are more sustainable, through providing an indepth appraisal of the context into which the plant will be "inserted". However, there is some indication that many baselining studies are carried out for the sake of legislative compliance only, and that all but the crucial compliance issues are rapidly forgotten in the subsequent design phase.

\subsubsection{Planning phase tools and efficacy criteria}

Examining the tools utilised at the planning phase in conjunction with the requirements in Table 2 , a number of observations are made in Table 3.

\subsection{Design phase}

When prefeasibility proceeds to design, four aspects are of key interest:

- Design methodologies

- Design tools and techniques

- Costing methods

- Decision-support tools

These areas of design were examined in the literature with specific reference to the minerals industry, although some tools have been more widely applied in other industries.

\subsubsection{Design methodologies}

The key conclusion of this review of sustainability in the design of mineral operations is that there is a notable lack of integration of SD principles in design of new plants, and that the work that has been done focuses on complying with regulations or comes at the end of the design process, when most key decisions have already been made. A number of authors have sought to develop design methodologies that overcome this flaw [41]. Azapagic et al. [21] go some way to addressing the "after-thought" or "compliance only" approach to design. They offer a methodology based on life cycle thinking that integrates sustainability at all stages of design. This simple, generic approach allows flexibility and works with various levels of accuracy within the operation design process.

Stewart et al. [42] describe an "evolutionary design for environment" methodology for the minerals industry, which focuses on the use of LCA, EIA and multi-criteria decision analysis (MCDA). They identify challenges in environmental design of minerals technologies:

- the limited availability of thermodynamic information covering the full spectrum of chemical conversions embodied in minerals technologies;

- the low grade of mineral ores (and as a result, the myriad of impurities which must be removed typically);

- the variability and non-homogeneity of ores resulting in significant variation between ore bodies, as well as over the life of a single mine;

- the large energy demand for physical transformations;

- the significant role of poorly understood particulate processes in beneficiation and refining;

- the relative conservatism of the industry for technological change, itself captured in the dominance of vendor-driven design solutions; and 
Table 3

Planning phase tools and efficacy criteria.

\begin{tabular}{|c|c|c|}
\hline & Criteria & Comments \\
\hline \multirow[t]{6}{*}{ Key requirements } & 1. Understanding of sustainability concepts & $\begin{array}{l}\text { The } 3 \text { key frameworks for sustainability assessment are able to provide } \\
\text { some insight into the principles of sustainability. However, there is some } \\
\text { doubt as to whether they would be sufficient as a stand-alone tool for this purpose. } \\
\text { Furthermore, there is a question as to the ability of each framework to encourage } \\
\text { development of indicators distinct to the project in question. The MMSD's } 7 \\
\text { Questions method is the most likely candidate to fulfil this criterion, although } \\
\text { the ICMM is most widely adopted by industry. These standardised frameworks } \\
\text { are useful, but could limit the conception of the user to a TBL approach, } \\
\text { with set indicators. }\end{array}$ \\
\hline & $\begin{array}{l}\text { 2. Understanding of the baseline context } \\
\text { of the project - key stakeholders, community, } \\
\text { local environment, economy and their interactions }\end{array}$ & $\begin{array}{l}\text { EIA and SIA can provide the baseline context for the project, although } \\
\text { they are limited by the fact that they may not have a sufficiently broad scope } \\
\text { or rigorous approach to identify all the key impacts. Furthermore, the interactions } \\
\text { of economy, society and environment are not often well examined. }\end{array}$ \\
\hline & $\begin{array}{l}\text { 3. Predicting potential impacts or benefits } \\
\text { on the environment, society and economy } \\
\text { at different scales }\end{array}$ & $\begin{array}{l}\text { EIA, SIA and LCA can examine environmental and social impacts at different scales, } \\
\text { but often the scope is limited. }\end{array}$ \\
\hline & $\begin{array}{l}\text { 4. Understanding of the limitations } \\
\text { of the local environment } \\
\text { and community, and any synergies } \\
\text { that might assist the project } \\
\text { or be supported by it }\end{array}$ & $\begin{array}{l}\text { EIA and SIA can potentially provide this, but do not commonly perform this function } \\
\text { well. Limitations of the environment are often examined in qualitative, rather } \\
\text { than quantitative terms, and legislative requirements typically taken } \\
\text { as pseudo-limitations. Synergies are not the key focus of either of these assessments, } \\
\text { but should be integrated for greater coverage of sustainability. }\end{array}$ \\
\hline & $\begin{array}{l}\text { 5. Understanding stewardship issues across product } \\
\text { and project life cycle phases that could require } \\
\text { or impose external or indirect impacts }\end{array}$ & $\begin{array}{l}\text { LCA can increase awareness of stewardship issues across the life cycle } \\
\text { of the project/product, but a greater focus could be placed on emphasising } \\
\text { stewardship in looking at the connectivity and flow-on effects of changes in the } \\
\text { project design. }\end{array}$ \\
\hline & $\begin{array}{l}\text { 6. Long term viability of environment, society } \\
\text { and economy with or without project - risk assessment }\end{array}$ & $\begin{array}{l}\text { The planning tools examined here, are once-off examinations of potential impacts. } \\
\text { They may include some examination of long term viability - and can certainly be } \\
\text { adapted to this end - but do not typically focus on this area specifically. }\end{array}$ \\
\hline \multirow[t]{4}{*}{$\begin{array}{l}\text { Additional } \\
\text { considerations }\end{array}$} & A. Developing a stakeholder engagement plan & $\begin{array}{l}\text { SIA can be used to develop a stakeholder engagement plan from the social } \\
\text { perspective, but does not typically cross-over to encompass all aspects of SD. }\end{array}$ \\
\hline & $\begin{array}{l}\text { B. Determining metrics for the measurement } \\
\text { of SD performance }\end{array}$ & $\begin{array}{l}\text { The ICMM SD framework (linking to the GRI metrics) gives a general set of metrics } \\
\text { for minerals operations. However, there is significant research indicating that such } \\
\text { general sets of metrics, while useful, do not provide a sense of "ownership" to the } \\
\text { users, nor do they explicitly give the context of the assessment. } \\
\text { Stakeholder involvement (as encouraged through the 7Q's method) is seen as an } \\
\text { important aspect of delivering meaningful SD metrics. }\end{array}$ \\
\hline & C. Necessity of project & This is typically not addressed by any tool. \\
\hline & $\begin{array}{l}\text { D. Effectively communicate/carry-over } \\
\text { learnings to design } \\
\text { and operations phases }\end{array}$ & $\begin{array}{l}\text { This is one particularly weak link in the overall process of design for sustainability } \\
\text { of an operation, with numerous consultants involved at the planning phase } \\
\text { (often different to the teams involved in other phases), and communication limited } \\
\text { to once-off reports or presentations. }\end{array}$ \\
\hline
\end{tabular}

- the environmental impacts of minerals processing often manifest themselves over a wider range of spatial and temporal scales than those of commodity chemicals.

Whilst not focusing on all elements of the TBL, "Green chemistry", "green engineering" and DfE are all closely linked (and sometimes interchangeable) concepts that aim to improve sustainability by reducing impact on the environment through changing processing pathways and eliminating damaging products, by-products. These methodologies aim to compare the impacts of different processing alternatives by determining indicators of the potential for process flows to impact on the environment [43-49]. Cano-Ruiz and McRae [20] offer a very comprehensive review of current practices in process plant DfE. However, as this review indicates, the majority of design methodologies look solely at the environmental aspects of sustainability, rather than considering the triple bottom line.

\subsubsection{Design tools and techniques}

Numerous design tools and techniques have been developed to aid in the improvement of specific elements of sustainability of process industry plants. The majority of these tools are readily transferrable (or have already been applied) to the minerals industry. The tools mentioned here (as with the majority of SD tools for industry) examine the environmental aspects of the process.
2.3.2.1. Life cycle assessment. Life cycle assessment is a widely recognised method of assessing the impacts of an operation or product over its whole life cycle, and has been applied to various different minerals processes [50-54]. LCA has been used as a tool in environmental assessments for many years, but perhaps the most important contribution of life cycle thinking, is the concept of stewardship of a product across its life cycle $[55,56]$. This concept is particularly interesting in regard to metals, with further complexity in the SD assessment due to the potential for recycling, and the subsequent reduction in energy and emissions per tonne of product [57]. It has been shown that a systems approach (as used in LCA) is valuable in discovering opportunities for development, financial savings, improvement of environmental performance [58] and the assessment of production per unit waste [59].

The LICYMIN database [60] is another example of a LCA methodology, developed in the EU, specifically for mining applications. Originally developed because of a lack of site-specificity and detail in the mining and minerals processing aspect of existing LCA software, it is not yet widely utilised.

2.3.2.2. Pollution prevention and waste minimisation. Pollution prevention and waste minimisation are commonly considered in process design to reduce operational impacts of a plant on the environment [61-63]. The most strategic point for intervention in terms of pollution prevention or waste minimisation 
(as for all sustainability considerations) is early on in the design process, whilst later 'end-of-pipe' solutions have reduced options and limited scope $[64,65]$.

Four major categories of pollution prevention approaches are commonly cited, listed here as per Fiksel [66]:

- Good housekeeping practices to ensure that resources are utilised efficiently and that preventable material losses are not occurring through leakage or excessive use;

- Material substitution to reduce or eliminate the presence of undesirable substances such as heavy metals, carcinogens, or CFCs;

- Manufacturing process changes to simplify production technologies, reduce water and energy use, or introduce closedloop recycling;

- Resource recovery to capture waste materials and reuse them either as inputs to other manufacturing processes or for secondary applications;

Optimisation of the process in terms of economics and environmental performance is often a key element of the pollution prevention strategy. Pinch analysis is highlighted as one of the key methodologies for optimisation, integration and reduction of pollution [67-69]. Pinch analysis is typically based on material and energy flows; however, similar methodologies for minimising pollution-related costs are also reported [70,71].

2.3.2.3. Eco-efficiency and cleaner production. Eco-Efficiency (EE) and Cleaner Production (CP) are system-focused approaches on reducing the environmental impacts of an operation or industry by reducing the waste or emissions per unit of product. $\mathrm{EE}$ and $\mathrm{CP}$ have been discussed specifically in relation to the mining industry elsewhere $[72,73]$. Further studies on the theme of waste minimisation and SD programs, including case studies, have also been completed $[74,75]$. Their focus on waste generation rates allows assessment of the wastefulness of an operation, but does not provide a measure of sustainable production.

2.3.2.4. Risk assessment tools. Another approach to sustainability assessment of process flowsheets has been to use risk assessment techniques. The mineral industry is familiar with the concept of risk management and assessment, but less so with the concepts and context of sustainability. The Site Level Opportunity and Threat Analysis tool (SOTA) is one tool that has been developed based on a risk assessment methodology [76]. The aim of the tool is to enable users to examine their operations in terms of sustainability opportunities and threats using a risk-based approach. The risk approach is useful in bringing qualitative or semi-quantitative risk elements into the decision process.

\subsubsection{Costing}

Costing of the project is an essential element in determining whether it will proceed or not. Standard engineering projects have been costed using a Net Present Value (NPV) approach, which relies on assumed internal rates of return, and does not typically incorporate any elements of wider social or environmental impact.

However, some financial methods can be applied, which attempt to incorporate the environmental and social costs of a project into an economic assessment. The concept of valuing externalities is a favoured approach by many authors, and requires the determination of an "appropriate" cost for all aspects of environmental and social impact (positive or negative) that are not included in the typical operational financial costs [77-79]. Many such assessments use a "willingness to pay" (WTP) approach, where stakeholders are surveyed to determine a cost based on the community's willingness to pay for environmental preservation, which is not an ideal method of gauging the actual value to society of a given resource, given the subjective nature of the estimate - as indicated by the variation based on demographic factors [80] and the difference between actual and hypothetical payments [81]. The Externalities of Energy project in the EU has, where possible, applied less subjective measures, through the use of historical health system data, and ecotoxicity methods [82].

A major examination of the methods of full cost accounting (FCA) was done in the production of the Sustainability Assessment Model (SAM) [83]. The SAM consists of an assessment of the economic, resource use, environmental and social impacts of a project over the life cycle of the product, with monetisation of all impacts for final comparison of a sustainability "signature" for the project [84]. From the numerous case studies of the application of FCA cited, perhaps the most important finding was that the knowledge was incomplete and required ongoing re-evaluation [84].

The "Real Options" methodology is an emerging, but potentially useful means of incorporating uncertainty and flexibility into the value of a project [85]. This is in contrast to the NPV approach which assumes a distinct path that the project will take [86]. Although the modelling can become quite complex, the minerals industry would seem to have a natural ability (in that all mines deal with stochastic processes and risk) to be able to integrate this approach. Mine closure events have been particularly studied, as the conditions for mine closure due to market changes are not well predicted under an NPV assessment [87]. The valuing of sustainable design options or flexibility to operate under changed regulatory regimes can be particularly important, and Real Options lends itself to this task.

Purely financial methods may be argued to be less transparent (they typically combine all impacts into a single final figure) and the costing procedures are often questionable. Further difficulties arise with this method when a global market is considered, in which environmental costs are not equally valued across national borders.

\subsubsection{Decision-making tools}

The multi-dimensional nature of sustainability, incorporating such a variety of both independent and interlinked environmental, economic and social elements across various time and spatial scales, leads to a wide range of quantitative and qualitative outputs that are difficult to integrate. A number of tools and methodologies have been developed to consolidate the data and to assist decision making.

Some of these methodologies involve economic costing of social and environmental impacts, whilst others rely on Multi-Criteria Assessment (MCA). MCA methods vary, but fundamentally involve the determination of impact on each of the criteria for a number of impact categories, followed by weighting and analysis of options [34,88-91]. Pohekar and Ramachandran [92] offer a comprehensive review of a variety of techniques in MCA applied to the sustainable energy planning.

A significant debate has continued in sustainability literature about the feasibility of integrating the various metrics into a single indicator or index. Arguments for this concept involve the ease of comparison for decision makers, whilst arguments against highlight the fact that weighting systems involve inherent, possibly subjective, bias and have the ability to be adapted to justify the desired outcome of any stakeholder.

Decision-support frameworks are used to allow a methodical, rigorous approach to decision making with multiple criteria. For example, Azapagic and Perdan [93,94] and Cohen et al. [95] have proposed decision-support frameworks for sustainability and sustainability in the minerals industry respectively. Ultimately, the people in positions of making the final decision on projects must be given as much possible information in as succinct and 
comprehensible form as possible. MCA tools can assist in this provision of information, but do not eliminate the need for subjective judgement in the final decision.

The design phase tools mentioned up to this point are examined against DfS criteria in Table 4.

\section{Discussion}

An important finding from this review is that there is a wide range of SD tools and methodologies that, can to varying degrees, contribute to Design for Sustainability (DfS). However, the integration of these tools into a comprehensive framework is not currently available.

Many of the current approaches to DfS involve an initial step of defining the problem and goals, both in a sustainability and an operational sense. This step is the earliest opportunity to bring a common understanding of sustainability and sustainable development issues to the design team. Importantly, local and global context needs to be integrated and considered in the design process, so that a project is designed in a way that most suits the sustainable

Table 4

Design phase tools and efficacy criteria.

\begin{tabular}{ll}
\hline Key requirements & $\begin{array}{l}\text { 1. Incorporate/integrate planning } \\
\text { phase understanding }\end{array}$ \\
& \\
& $\begin{array}{l}\text { 2. Understanding the effect of design } \\
\text { choices on direct and indirect SD impacts } \\
\text { of the project: } \\
\text { i. Environmental emissions } \\
\text { and resource usage across the product } \\
\text { and project life cycle; }\end{array}$
\end{tabular}

i. Onsite and offsite effects;

ii. Closure and recycling impacts

iii. Industrial and social synergies

iv. Waste reduction/by-product reuse;

v. Construction and operational impacts

vi. Deviation from baseline impacts and social/ environmental limitations

vii. Human/environmental/economic costs and benefits

3. Creation and comparison of alternatives based on SD impacts

4. Incorporation of stakeholder input

5. Costing methods including

non-financial SD impacts

6. Optimisation and decision-making based on an inclusive SD approach

Additional A. Innovation considerations
Comments

There is little evidence in the literature, of any consistent method of integrating planning phase understanding into the design of industrial operations. The only common example is the reduction of risk by compliance with environmental regulation, subsequent to the EIA. DfE has the potential to bring this understanding across, but the separation of design and planning phase teams can cause discontinuity, which is difficult to bridge in an ad hoc manner.

The direct impacts of the project are more readily measured and observed than flow-on or indirect impacts. The concept of stewardship is potentially useful across all phases of the project.

Cleaner production, pollution prevention and Green Chemistry are tools/methodologies that examine the emissions and resource usage of the project, however their focus is often limited to the operation or production phase at hand, not examining further up or down the value chain. LCA takes full life cycle approach, but its efficacy in the design phase can be limited by time and resource availability. Some first-run LCA or footprint tools are available to assist in this - e.g. 4QA, FutureWatch [103].

HAZOP examines the onsite safety risks and onsite environmental effects are examined in an environmental management plan, but offsite effects seem to be largely relegated to compliance with legislation. Effective legislation can be seen in this context as an externally-applied DfS tool LCA can take recycling into account however design for closure is not an apparently widespread practice.

Regional Synergies/Industrial Ecology methods have significant research and (sometimes) commercial interest, but are not yet common practice for environmental sustainability improvement. Social synergies (such as shared infrastructure) are not often addressed at the design stage. Community engagement and employment/educational strategies are becoming more prevalent.

Cleaner production and pollution prevention methodologies aim to reduce waste. CP and IE focus on by-product reuse.

No specific tools address the construction impacts, which are most likely to be addressed in the EIA. Operational impacts of the plant are addressed by CP, LCA, etc. but personnel and other operational impacts are not.

Deviation from baseline environmental impacts are typically only examined in terms of legislative compliance. Social impacts are not often examined at the design stage. Limitations in the surrounding environment are not commonly examined. SIA and EIA can be extended/repeated during design to incorporate these limitations.

Examination of all of these elements is typically at the planning phase, rather than during design. Design phase elements are typically safety and financial cost. Methods for incorporating SD considerations are limited, but proprietary approaches are sometimes used by engineering companies.

At each stage of design, alternatives can be (and often are) created, but they are largely assessed on economic, safety and technical performance only. MCA methods can be used to assess alternatives based on SD impacts, but there is scope for methods to effectively create and compare alternatives.

Effective methods for stakeholder (other than client) input into the design phase are not apparent. The key avenue for stakeholder input seems to be in the planning phase.

NPV is typically used to cost the project, but externalities or real options approaches are more useful in an SD context. Non-financial examination of costs and benefits is not typically considered as a design parameter, but can be assessed using MCA methods.

TBL or SD-based decision making could be supported by MCA methods, but these are not often applied at present.

Generation of alternative and innovative processes can be enhanced using CP, DfE and green chemistry methods, but are difficult (or perhaps impossible) to "formalise". Workshop approaches are used elsewhere - e.g. SOTA, [76] SOHO [102] - and would seem to provide a logical semi-structured approach.

B. Best practice technologies
Sharing information on best practice technologies, and willingness of designers and clients to use them, are key challenges to uptake. SD outcomes could be improved by their implementation in many cases, so a method of dissemination would be useful. 
development requirements of the location in which it will have greatest impact. The understanding of interactions and potential synergies between the society, environment, and economy with the proposed project is a necessary element of DfS, which is largely lacking in current practice.

Developing alternatives is typically the next step in design processes, include a screening stage where alternatives can be developed (ideas generation is important here - and often overlooked!), examined, analysed and compared. The choice of process route or technology at this stage is the focus of most SD design work; however, there is little description of methods for achieving alternative design development. The need for systematic, rigorous and defendable methods of comparing alternatives effectively, such as multi-criteria analysis, is apparent from the literature. In a concept involving so many factors - both qualitative and quantitative - it is essential to be able to provide a level of decision support to take some of the subjectivity out of the decision.

To create appropriate alternatives in a DfS methodology, there is a need to integrate life cycle thinking and a focus on system interactions (at the operation itself, and across the product chain and local environment). Most sustainable design methodologies neglect the social aspect of sustainability, mainly due to the difficulty in dealing with qualitative data. However, there are examples that consider broader sustainability criteria, like need, intergenerational equity, and consent that reside close to the heart of sustainability. Social impact tools can help to draw in the societal interactions with the operation. They are currently used predominately to provide a baseline and deal with operational and closure impacts, rather than integrating into the design phase; however, stakeholder processes may be one method of incorporating social tools in design, although it is poorly defined in current technical approaches. By integrating the input of internal and external stakeholders into project design, the path to an operation with improved SD credentials will be smoother.

Another essential aspect of an integrated DfS mechanism is the transfer of knowledge or understanding between phases of the project development. From the review of current tools and the structure of the project phases of development, it is apparent that the understanding of the concept and context of sustainability of a project is not consistent across its stages. This is not surprising as many of the baselining studies are performed by specialist consultants, while the multiple areas of plant design are performed by separate design teams, and finally separate and often-changing teams of operators run the operation in the production phase. A rigorous mechanism for transfer of understanding is vital - especially in the planning and design phases - if an operation is to be sustainable. Different phases of the project-production cycle will have different requirements for integrating sustainability, but, an integrated, consistent, project and operation-wide framework for sustainability thinking would aid significantly in transfer of knowledge, understanding and development of cohesive DfS alternatives and initiatives.

Another point worth considering at the beginning of the design process is the societal need to develop the deposit under consideration in the first place. For instance, some commentators have asked "Should we develop a new gold mine if its end use is as gold bullion (for financial security) or jewellery?". This question, and similar ones for other commodities, has significant philosophical elements which are beyond the scope of this review but are worthy of further debate in the context of SD and the mineral industry. One example of sustainability assessment incorporating strong sustainability principles was the assessment of Tulsequah Chief Mine in British Columbia [31]. The assessment did not follow a TBL approach, but derived performance measures in terms of underlying sustainability principles. Consideration of the fundamental need of society for the mined product was seen as a key element in this assessment - beyond the needs of company and government stakeholders, and with an emphasis on recycling and efficiency of usage before new mining operations were considered. To preclude mining on the basis of such need is outside the current corporate or societal mentality.

A key finding from this review study is that while there are a range of tools and methodologies that contribute to DfS, there is no consistent, integrated approach to support the minerals industry in incorporating a greater level of sustainability into the design process. An approach of this nature would provide a rigorous and structured mechanism for integrating sustainability principles into process plant design and utilise the currently available tools and methodologies. If widely adopted by the minerals industry, it would give a greater level of security that a full range of sustainability aspects had been considered, evaluated and, where appropriate, implemented in the design or expansion of minerals processing operations. The degree of rigour that would be applied in the approach could conceivably provide a smoother path for development from regulatory, investment (with particular reference to the Equator Principles) and community perspectives.

The authors are currently involved with a research program through the Co-operative Research Centre for Sustainable Resource Processing $(\text { CSRP })^{3}$ that is developing a mechanism, called SUSOP ${ }^{\circledR}$ (SUStainable OPerations) which would satisfy the above criteria. $\mathrm{SUSOP}^{\circledR}$ aims to become a comprehensive and rigorous mechanism to generate feasible options according to SD principles, evaluate the sustainability benefits and impacts of these options, assess each option using an SD-based decision-support process and provide support for engineering and project management as well as the subsequent operation of projects. Still in the conceptual phase, the development of SUSOP ${ }^{\circledR}$ is progressing through industry-based case studies and the collaborative efforts from research and industry partners in CSRP.

\section{Conclusions}

A comprehensive review of literature in the area of sustainability in the mineral industry, with a key focus on the design of sustainable mineral operations, was conducted. The aim of the review was to identify how currently available tools and methodologies contribute to a comprehensive approach for Design for Sustainability (DfS) from a mineral processing perspective. It was apparent that, in order to develop more sustainable processes, key elements of a DfS methodology should include:

- an integrated, consistent, project and operation-wide framework for sustainability thinking;

- initial definition of the problem in sustainability terms, and with an eye to local context;

- generation of alternatives which incorporate sustainability goals;

- assessment of alternatives to compare SD impacts on at least a triple bottom line basis, most likely with some kind of MultiCriteria Assessment;

- involvement of stakeholders in prioritisation of sustainability goals and for feedback on alternatives; and,

- life cycle thinking and a focus on system interactions (at the operation itself, and across the product chain and local environment).

\footnotetext{
${ }^{3}$ Co-operative Research Centre for Sustainable Resource Processing (CSRP) was established in 2003 under the Australian Government's Co-operative Research Centres Program, with a vision of meeting the global material needs of society with a fraction of current ecological impacts. Further details are available at www.csrp. com.au.
} 
If the above facets could be incorporated into a DfS mechanism and if the mechanism can be widely adopted in the mineral industry, it could conceivably provide a smoother development path for all stakeholders.

\section{Acknowledgements}

This project is carried out under the auspice and with the financial support of the Centre for Sustainable Resource Processing, which is established and supported under the Australian Government's Cooperative Research Centres Program.

\section{References}

[1] Price Waterhouse Coopers. Mining and minerals sustainability survey. Report for the MMSD. London: PWC; 2001. p. 12.

[2] IIED, WBSCD. Breaking new ground: mining minerals and sustainable development final report. Report for the MMSD, London: Earthscan Publications Ltd; 2002. p. 4, 15-21.

[3] Stewart M, Petrie J. Planning for waste management and disposal in minerals processing using life cycle assessment. Min Energy Raw Mater Rep 1999;14(3):14-36

[4] Giurco D, Petrie JG. Strategies for reducing the carbon footprint of copper: new technologies, more recycling or demand management? Min Eng 2007;20(9):842-53.

[5] Cleveland CJ, Ruth M. Indicators of dematerialization and the materials intensity of use. J Ind Ecol 1998;2(3):15-50.

[6] Robèrt K-H. Tools and concepts for sustainable development, how do they relate to a general framework for sustainable development, and to each other? J Clean Prod 2000;8(3):243-54.

[7] Schmidt-Bleek F. The fossil makers. Berlin: Birkhäuser; 1993.

[8] Tilton J. Exhaustible resources and sustainable development. Resour Pol 1996;22(1-2):91-7.

[9] Dalvi AD, Bacon WG, Osborne RC. The past and future of Nickel laterites (Technical session nickel: current exploration and development solutions to near-term nickel shortages, paper 4). In: PDAC 2004 international convention, trade show and investors exchange. Toronto, Canada: Prospectors and Developers Association of Canada. Available online at: http://www.pdac.ca/ pdac/publications/papers/2004/techprgm-dalvi-bacon.pdf; 7-10 March, 2004 [accessed 28.05.09.].

[10] Graedel T, Klee R. Getting serious about sustainability. Environ Sci Technol 2002;36(4):523-9.

[11] Mudd GM. The sustainability of mining in australia: key production trends and their environmental implications for the future; 2007. p. iii.

[12] Stewart M, Weidema B. A consistent framework for assessing the impacts from resource use: a focus on resource functionality. Int J Life Cycle Assessment 2005;10(4):240-7.

[13] van Berkel R. Eco-efficiency in the Australian minerals processing sector. J Clean Prod 2007;15(8-9):772-81.

[14] McLellan B. Location-specific sustainability metrics for hydrogen energy systems. PhD thesis, University of Queensland, Brisbane, Australia; 2007. p. 19.

[15] McElroy MW, Jorna RJ, van Engelen J. Sustainability quotients and the social footprint. Corp Soc Responsibility Environ Manage 2008;15:223-34.

[16] Giurco D. Towards sustainable metal cycles: the case of copper. PhD thesis, Department of Chemical Engineering. Sydney, Australia, University of Sydney; 2005. p. 44-50.

[17] ICMM. Planning for integrated mine closure: toolkit. London: International Council on Mining and Metals; 2008. p. 4-81.

[18] Boks C, Diehl JC. Integration of sustainability in regular courses: experiences in industrial design engineering. J Clean Prod 2006;14(9-11):932-9.

[19] Pereira H, Souza P. Design for sustainability: methods in search for a better harmony between industry and nature. In: Fifth conference of the European academy of design, Barcelona, 2003 (design explaining sustainability session, paper 1).

[20] Cano-Ruiz JA, McRae GJ. Environmentally conscious chemical process design. Ann Rev Energy Environ 1998;23(1):499-536.

[21] Azapagic A, Millington A, Collett A. A methodology for integrating sustainability considerations into process design. Trans IChemE A 2006;84(A6):439-52.

[22] Dewulf W. Design for sustainability - anticipating the challenge. In: International conference on engineering design, Stockholm; 2003.

[23] Hardi P, Zdan TJ. Assessing sustainable development: principles in practice. Winnipeg, Canada: International Institute for Sustainable Development; 1997. p. 1.

[24] IISD. Seven questions to sustainability: how to assess the contribution of mining and minerals activities. Winnipeg (MA), Canada: International Institute for Sustainable Development; 2002.

[25] ICMM. ICMM sustainable development framework. London: International Council on Mining and Metals; 2003. p. 2-17.
[26] MCA. Enduring value: an Australian minerals industry framework for sustainable development. Canberra, Australia: Minerals Council of Australia; 2004. p. 2-32.

[27] GRI. An abridged version of the 2002 sustainability reporting guidelines: integrated with the draft mining and metals sector supplement. Amsterdam, The Netherlands: International Council of Mining and Minerals; 2004. p. 2-41.

[28] GRI. Sustainability reporting guidelines. Amsterdam, Netherlands: Global Reporting Initiative; 2006. p. 3-38.

[29] Fiksel DG, Garvin L, Brunetti T. Substudy 3: business case development. In: Toward a sustainable cement industry. Switzerland: World Business Council for Sustainable Development; 2002. p. 1-23.

[30] UNEP. Berlin II - guidelines for mining and sustainable development. Nairobi, Kenya: United Nations Environment Program; 2002. p. 4.

[31] Green TL. Evaluating mining and its effects on sustainability: the case of the Tulsequah Chief Mine. Vancouver, Canada: Environmental Mining Council of British Columbia; 2001.

[32] Gibson RB. Sustainability assessment: basic components of a practical approach. Impact Assess Proj Apprais 2006;24:170-82.

[33] Robert KH, Schmidt-Bleek B, Aloisi de Larderel J, Basile G, Jansen JL, Kuehr R, et al. Strategic sustainable development - selection, design and synergies of applied tools. J Clean Prod 2002;10(3):197-214.

[34] Janssen R. On the use of multi-criteria analysis in environmental impact assessment in the Netherlands. J Multi-Criteria Decis Anal 2001:10:101-9.

[35] Gilpin A. Environmental impact assessment: cutting-edge for the twentyfirst century. Cambridge, UK: Cambridge University Press; 1995. p. 20-146.

[36] Labuschagne C, Brent AC. Social indicators for sustainable project and technology life cycle management in the process industry. Int $\mathrm{J}$ Life-cycle Assessment 2006;11:3-15

[37] Howitt R. Social impact assessment and resource development: issues from the Australian experience. Aust Geogr 1989;20(2):153-66.

[38] Joyce SA, MacFarlane M. Social impact assessment in the mining industry: current situation and future directions. London: International Institute for Environment and Development (IIED)-Mining, Minerals and Sustainable Development; 2001. p. 8-10.

[39] Van Berkel R, Bossilkov A, Harris S. Opportunities and constraints for regional resource synergies in minerals processing regions. In: Herbertson J, Rankin J, Jahanshahi S, editors. Proceedings of Green Processing 2006, Newcastle, Australia; 2006. p. 113-24.

[40] Corder G, van Beers D, Lay J, van Berkel R. Benefits and success factors of regional resource synergies in Gladstone and Kwinana. In: Herbertson J, Rankin J, Jahanshahi S, editors. Proceedings of Green Processing 2006 Newcastle, Australia; 2006. p. 83-92.

[41] Swinkels PLJ, van der Weijden RD, Ajah AN, Arifin Y, Loe HL, Manik MH, et al. Conceptual process design as a prerequisite for solving environmental problems; a case study of molybdenum removal and recovery from wastewater. Min Eng 2004;17(2):205-15.

[42] Stewart M, Basson L, Petrie JG. Evolutionary design for environment in minerals processing. Process Saf Environ Prot 2003;81:341-51.

[43] Fu Y, Diwekar UM, Young D, Cabezas H. Process design for the environment: a multi-objective framework under uncertainty. Clean Prod Process 2000;2(2):92-107.

[44] Young D, Scharp R, Cabezas H. The waste reduction (WAR) algorithm: environmental impacts, energy consumption, and engineering economics. Waste Manag 2000;20(8):605-15.

[45] Young DM, Cabezas H. Designing sustainable processes with simulation: the waste reduction (WAR) algorithm. Comput Chem Eng 1999;23(10):1477-91.

[46] Smith RL. Evaluating the economics and environmental friendliness of conceptual designs for new and retrofitted chemical processes. Clean Technol Environ Policy 2002;3:383-91.

[47] Gonzalez MA, Smith RL. A methodology to evaluate process sustainability Environ Prog 2003;22(4):269-76.

[48] Smith RL, Gonzalez MA. Methods for evaluating the sustainability of green processes. In: Barbosa-Povoa A, Matos H, editors. Proceedings of European Symposium on Computer-Aided Process Engineering, 14, Lisbon, Portugal. Computer-Aided Chemical Engineering, 18; 2004. p. 1135-40.

[49] Curzons A, Constable DJC, Mortimer DN, Cunningham VL. So you think your process is green, how do you know? - using principles of sustainability to determine what is green - a corporate perspective. Green Chem 2001;3(1):1-6.

[50] Norgate TE, Jahanshahi S, Rankin WJ. Assessing the environmental impact of metal production processes. J Clean Prod 2007;15(8-9):838-48.

[51] Stewart M, Petrie J. A process systems approach to life cycle inventories for minerals: South African and Australian case studies. J Clean Prod 2006;14(12-13):1042-56.

[52] Olivieri G, Romani A, Neri P. Environmental and economic analysis of aluminium recycling through life cycle assessment. Int J Sustainable Develop World Ecol 2006;13(4):269.

[53] Wibberley L. LCA - a tool for sustainability. Workshop on life cycle assessment in APEC environmental co-operation workshop (ECOW'99) - sustainable development of mining activities, Cairns, 5th-8th October, 1999.

[54] Norgate TE, Rankin WJ. Life cycle assessment of copper and nickel production. Melbourne, Australia: Australasian Institute of Mining and Metallurgy; 2000.

[55] DITR. Stewardship. In: Leading practice sustainable development program for the mining industry. Canberra, Australia: Australian Government, Department of Industry, Tourism and Resources; 2006. p. 1-55. 
[56] ICMM. Maximising value: guidance on implementing materials stewardship in the minerals and metals value chain. London: International Council on Mining and Metals; 2006. p. 1-36.

[57] Norgate TE, Rankin WJ. The role of metals in sustainable development. In: Green processing, international conference on the sustainable processing of minerals Cairns, QLD, Australia. Australasian Institute of Mining and Metallurgy; 2002. p. 49-55.

[58] Bossel H. Indicators for sustainable development: theory, method, applications. Winnipeg: International Institute for Sustainable Development; 1999 p. 1-124.

[59] Norgate TE, Lovel RR. Sustainable water use in minerals and metal production. In: Herbertson J, Rankin J, Jahanshahi S, editors. Proceedings of Green Processing 2006, Newcastle, Australia; 2006. p. 133-44.

[60] Durucan S, Korre A, Munoz-Melendez G. Mining life cycle modelling: a cradle-to-gate approach to environmental management in the minerals industry. J Clean Prod 2006;14(12-13):1057-70.

[61] Allen DT, Rosselot KS. Pollution prevention for chemical processes. New York: John Wiley; 1997. p. 1-162.

[62] Berger SA. The pollution prevention hierarchy as an R\&D management tool. AIChE Symp Ser 1995:1-6. Pollution Prevention Through Process and Product Modifications.

[63] Douglas JM. Process synthesis for waste minimization. Ind Eng Chem Res 1992;31(1):238-43.

[64] Anastas PT, Breen JJ. Design for the environment and green chemistry: the heart and soul of industrial ecology. J Clean Prod 1997;5(1-2):97-102.

[65] Pistikopoulos EN, Stefanis SK, Livingston AG. A methodology for minimum environmental impact analysis. AIChE Symp Ser 1994;90(303):139-50.

[66] Fiksel J. Design for environment: creating eco-efficient products and processes. United States: McGraw-Hill; 1996. p. 1-513.

[67] Tan RR, Sum Ng DK, Yee Foo DC. Pinch analysis approach to carbon-constrained planning for sustainable power generation. J Clean Prod 2009;17(10):940-4.

[68] El-Halwagi MM. Pollution prevention through process integration: systematic design tools. Academic Press; 1997. p. 1-314.

[69] Schollenberger H, Treitz M, Geldermann J, Rentz O. Multi objective pinch analysis (MOPA) using PROMETHEE to evaluate resource efficiency. In: Operations Research Proceedings 2005; 2006. p. 565-570.

[70] Kemp IC. Pinch analysis and process integration. 2nd ed. London: Butterworth-Heinemann; 2007. p. 87-89.

[71] Rossiter AP, Kumana JD. Rank pollution prevention and control options. Chem Eng Prog 1994;90(2):39-44.

[72] Hilson G. Pollution prevention and cleaner production in the mining industry: an analysis of current issues. J Clean Prod 2000;8(2):119-26.

[73] Hilson G. Defining "cleaner production" and "pollution prevention" in the mining context. Min Eng 2003;16(4):305-21.

[74] Driussi C, Jansz J. Pollution minimisation practices in the Australian mining and mineral processing industries. J Clean Prod 2006;14(8):673-81.

[75] Driussi C, Jansz J. Technological options for waste minimisation in the mining industry. J Clean Prod 2006;14(8):682-8.

[76] Evans R, Joy J. Development of a site level sustainability opportunity and analysis tool. Brisbane, Australia: Sustainable Minerals Institute for the Australian Coal Association Research Program; 2003. p. 1-43.

[77] Roper A. Mining and sustainable development: associations hold key to programme of change. Ind Environ 2000;23(SPEC ISS):26-9.

[78] Steen B, Borg G. An estimation of the cost of sustainable production of metal concentrates from the earth's crust. Ecol Econ 2002;42(3):401-13.

[79] Damigos D, Kaliampakos D. The "battle of gold" under the light of green economics: a case study from Greece. Environ Geol 2006;50(2):202-18.

[80] Solomon BD, Johnson NH. Valuing climate protection through willingness to pay for biomass ethanol. Ecol Econ 2009;68(7):2137-44.

[81] Foster V, Bateman IJ, Harley D. Real and hypothetical willingness to pay for environmental preservation: a non-experimental comparison. J Agric Econ 1997;48(1-3):123-37.
[82] European Commission.. Externalities of energy (ExternE) methodology 2005 update. In: Bickel P, Friedrich R, editors; 2005. p. 1-268.

[83] Bebbington J, Gray R, Hibbitt C, Kirk E. Full cost accounting: an agenda for action. London: Certified Accountants Educational Trust; 2001. p. 5-160.

[84] Bebbington J, Frame B. Moving from SD reporting to evaluation: the sustainability assessment model. Chartered Account J 2003;82(7):p11-13.

[85] Graham P, Vincent D, Coombes P, Duffy G. Real options analysis - a case study. Brisbane, Australia: CSIRO Energy Technology Report for Cooperative Research Centre Coal in Sustainable Development; 2003. p. 1-49.

[86] Slade M. Managing projects flexibly: an application of real-option theory. Discussion Paper No.98-02. Vancouver, Canada: University of British Columbia. Available online: www.edcon.ubc.ca/dp9802.pdf; 1998 [accessed 28.05.09]

[87] Moel A, Tufano P. When are real options exercised? An empirical study of mine closings. Rev Financ Stud 2002;15(1):35-64.

[88] De Marchi B, Funtowicz SO, Lo Cascio S, Munda G. Combining participative and institutional approaches with multicriteria evaluation. An empirical study for water issues in Troina, Sicily. Ecol Econ 2000;34:267-82.

[89] Munda G, Nijkamp P, Rietveld P. Environmental decision-making: a comparison between cost-benefit analysis and multicriteria decision aid. In: Faucheux S, O'Conner M, van der Straaten J, editors. Sustainable Development: Concepts, Rationalities and Strategies. Dordrecht: Kluwer Academic Publishers; 1998. p. 227-38.

[90] Rauschmayer F. Reflections on ethics and MCA in environmental decisions. J Multi-Criteria Decis Anal 2001;10:65-74.

[91] Munda G. Measuring sustainability: a multi-criterion framework. Environ Develop Sustainability 2005;7(1):117-34. doi:10.1007/s10668-003-4713-0.

[92] Pohekar SD, Ramachandran M. Application of multi-criteria decision making to sustainable energy planning - a review. Renewable Sustainable Energy Rev 2004;8(4):365-81.

[93] Azapagic A, Perdan S. An integrated sustainability decision-support framework part I: problem structuring. Int J Sustainable Develop World Ecol 2005;12(2):98.

[94] Azapagic A, Perdan S. An integrated sustainability decision-support framework part II: problem analysis. Int J Sustainable Develop World Ecol 2005;12(2):112.

[95] Petrie J, Cohen B, Stewart M. Decision support frameworks and metrics for sustainable development of minerals and metals. Clean Technol Environ Policy 2007;9(2):133-45.

[96] Allen D, Consoli F, Davis G, Fava J, Warren J. Public policy applications of lifecycle assessment. Penascola, USA: Society for Environmental Toxicology and Chemistry (SETAC); 1997. 1-127.

[97] ICMM. Materials stewardship: Eco-efficiency and product policy. London: International Council on Mining \& Metals; 2007. p. 1-15.

[98] Anastas PT, Warner JC. Green chemistry: theory and practice. Oxford, U.K.: Oxford University Press; 1998. p. 1-120.

[99] Kletz TA. Hazop and Hazan: identifying and assessing process industry hazards. Rugby, UK: Institution of Chemical Engineers; 1999. p. 1-223.

[100] Crawley F, Preston M, Tyler B. HAZOP: Guide to best practice: guidelines to best practice for the process and chemical industries. Rugby, UK: Institution of Chemical Engineers; 2000. p. 1-101.

[101] Evans R, Brereton D, Joy J. Risk assessment as a tool to explore sustainable development issues: lessons from the Australian coal industry. Int J Risk Assess Manag 2007;7(5):607-19.

[102] Gale S, Bangerter P, Mackay T. Sustainability and steel: a matter of application and innovative design. In: Material, minerals, and metal ecology 06, Johannesburg, November 14-15, 2006 (technical session 1, paper 2).

[103] Bangerter P, Kwak J. Sustainable plant design. In: Metallurgical plant design and operating strategies. Perth, Australia: The Australasian Institute of Mining and Metallurgy; 2004 